\title{
Influence of Age, Health, and Function on Cancer Screening in Older Adults with Limited Life Expectancy
}

\author{
Nancy L. Schoenborn, $M D, M H S^{1,2}$, Jin Huang, $M S^{1,2}$, Orla C. Sheehan, $M D, P h D^{1,2}$, \\ Jennifer L. Wolff, $P h D^{2,3}$, David L. Roth, $P h D^{1,2}$, and Cynthia M. Boyd, MD, MPH ${ }^{1,2}$ \\ ${ }^{1}$ The Johns Hopkins School of Medicine, Baltimore, MD, USA; ${ }^{2}$ The Johns Hopkins Center on Aging and Health, Baltimore, MD, USA; ${ }^{3}$ The Johns \\ Hopkins School of Public Health, Baltimore, MD, USA.
}

BACKGROUND/OBJECTIVES: We examined the relationship between cancer screening and life expectancy predictors, focusing on the influence of age versus health and function, in older adults with limited life expectancy.

DESIGN: Longitudinal cohort study

SETTING: National Health and Aging Trends Study (NHATS) with linked Medicare claims.

PARTICIPANTS: Three cohorts of adults 65+ enrolled in fee-for-service Medicare were constructed: women eligible for breast cancer screening $(n=2043)$; men eligible for prostate cancer screening $(n=1287)$; men and women eligible for colorectal cancer screening $(n=3759)$.

MEASUREMENTS: We assessed 10-year mortality risk using 2011 NHATS data, then used claims data to assess 2-year prostate and breast cancer screening rates and 3year colorectal cancer screening rates. Among those with limited life expectancy (10-year mortality risk > 50\%), we stratified participants at each level of predicted mortality risk and split participants in each risk stratum by the median age. We assembled two sub-groups from these strata that were matched on predicted life expectancy: a "younger sub-group" with relatively poorer health/ functional status and an "older sub-group" with relatively better health/functional status. We compared screening rates between sub-groups.

RESULTS: For all three cancer screenings, the younger sub-groups (average ages 73.4-76.1) had higher screening rates than the older sub-groups (average ages 83.686.9); screening rates were $42.9 \%$ versus $34.2 \%$ for prostate cancer screening ( $p=0.02$ ), $33.6 \%$ versus $20.6 \%$ for breast cancer screening ( $p<0.001), 13.1 \%$ versus $6.7 \%$ for colorectal cancer screening in women $(p=0.006)$, and $20.5 \%$ versus $12.1 \%$ for colorectal cancer screening in men $(p=0.002)$

CONCLUSION: Among older adults with limited life expectancy, those who are relatively younger with poorer health and functional status are over-screened for cancer at higher rates than those who are older with the same predicted life expectancy.

Received February 8, 2018

Revised September 11, 2018

Accepted September 11, 2018

Published online November 6, 2018
KEY WORDS: geriatrics; cancer screening; health status; functional status.

J Gen Intern Med 34(1):110-7

DOI: $10.1007 / \mathrm{s} 11606-018-4717-\mathrm{y}$

(c) Society of General Internal Medicine 2018

\section{INTRODUCTION}

The benefit of cancer screening takes many years to accrue while the harms are more immediate. ${ }^{1-13}$ There is a lag time of at least 10 years before patients screened for breast, colorectal, or prostate cancers derive benefit. ${ }^{2,8,11,12}$ On the other hand, multiple harms from screening can occur in the short term, such as complications from screening and follow-up tests, overtreatment of clinically unimportant cancers, psychological stress from false positive results, diverted attention from other health conditions or more impactful health interventions, and increased burden for patients. ${ }^{1,3-13}$ Therefore, cancer screening in older adults with limited life expectancy may inappropriately subject them to harm with little chance of benefit.

Traditionally, age has been used as a proxy for life expectancy, but a growing body of literature demonstrates that older adults of the same age can have very heterogeneous health status and health trajectories. ${ }^{1} 14$ For this reason, clinical practice guidelines increasingly use limited life expectancy, often defined as $<10$ years, to guide when routine cancer screening should stop, as opposed to using only age thresholds. ${ }^{13,15-18}$ However, the screening rate among older adults with limited life expectancy remains high despite little chance for benefit and greater probability of harm. ${ }^{19-23}$

In addition to age, health status and functional status factors are also important predictors of life expectancy. ${ }^{24,25}$ In our prior work, we found that clinicians were reluctant to stop screening when the older adult with limited life expectancy was relatively younger (e.g., 60-year-olds compared to 80 -year-olds), ${ }^{26}$ suggesting that younger age may be more influential in the screening decisions than other life expectancy predictors. A few studies have explored the relationship between age, life expectancy, and cancer screening in national samples but yielded contradicting findings regarding whether age is associated with 
screening independent of mortality risk. $.^{19,} 20,27-29$ We aimed to extend this body of literature by examining the relationship between different predictors of mortality risk in older adults, in particular focused on the influence of age versus health and functional status, and receipt of cancer screening in a nationally representative cohort of older adults.

\section{METHODS}

\section{Data Source and Study Sample}

We draw on data from the National Health and Aging Trends Study (NHATS) linked to Medicare claims. NHATS is a population-based survey of health and disability trends among Medicare beneficiaries aged 65 years and older with focus on late-life functioning. Annual, in-person interviews collect detailed information from participants regarding their physical and cognitive health, social environment, and participation in daily activities. The NHATS design and procedures have been described previously. ${ }^{30}$ For this study, we included community-dwelling older adults who responded to the first wave of NHATS in 2011 (response rate 71\%). We constructed three separate cohorts in which we identified subsets of older adults eligible for each type of cancer screening (breast, colorectal, and prostate) who were continuously enrolled in feefor-service Medicare for the relevant time period (Fig. 1). Participants for whom we did not have access to complete information necessary for predicting life expectancy (see subsequent section "Life Expectancy Estimates") were excluded $(n=355)$. We used published algorithms to exclude those ineligible for screening using claims data in the previous 1 year (2010-2011). ${ }^{31-33}$ We then followed study participants forward in time using claims data to assess screening rates over the relevant observation period. For breast and prostate cancer screenings, we assessed rates of screening mammograms and prostate-specific antigen (PSA) tests, respectively, over a 2year period (2011-2013) because recommended intervals for these two screening tests range from annually to biennially. ${ }^{10}$, 13, 15, 16, 34 For colorectal cancer screening, we included any screening colonoscopy, sigmoidoscopy, or fecal occult blood test during the study period. The recommended interval for colorectal cancer screening is 10 years using colonoscopy, 5 years using sigmoidoscopy, and yearly using fecal occult blood test. ${ }^{9,35}$ Our observation period was limited through 2014 and we therefore measured screening rate over the time period 2011-2014. Details of screening test identification in the claims data are described in the Appendix. Study participants who died before the end of the observation periods were included in the analyses. This project was approved by a Johns Hopkins School of Medicine institutional review board.

\section{Life Expectancy Estimates}

We used an index developed by Lee et al. to estimate the 10year mortality risk of the study participants. ${ }^{24}$ This index incorporates information on both health and function, is applicable to community-dwelling older adults, has excellent discrimination with a $c$-statistic of 0.834 , and is quantified using questions available from the NHATS interviews, and its 10 -year time frame is the estimated time horizon for benefit

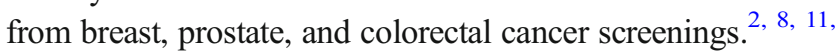
${ }^{12}$ Several cancer screening guidelines define limited life expectancy as less than 10 years. ${ }^{13,17,36}$ Accordingly, we defined limited life expectancy in this study as those with > $50 \%$ 10-year mortality risk, which corresponds to a median life expectancy of less than 10 years.

The Lee index (Table 1) employs 12 items including age, sex, health status/comorbidities (body mass index, diabetes, cancer, lung disease, heart disease, smoking), and functional

\section{NHATS 2011 Community-dwelling Participants}
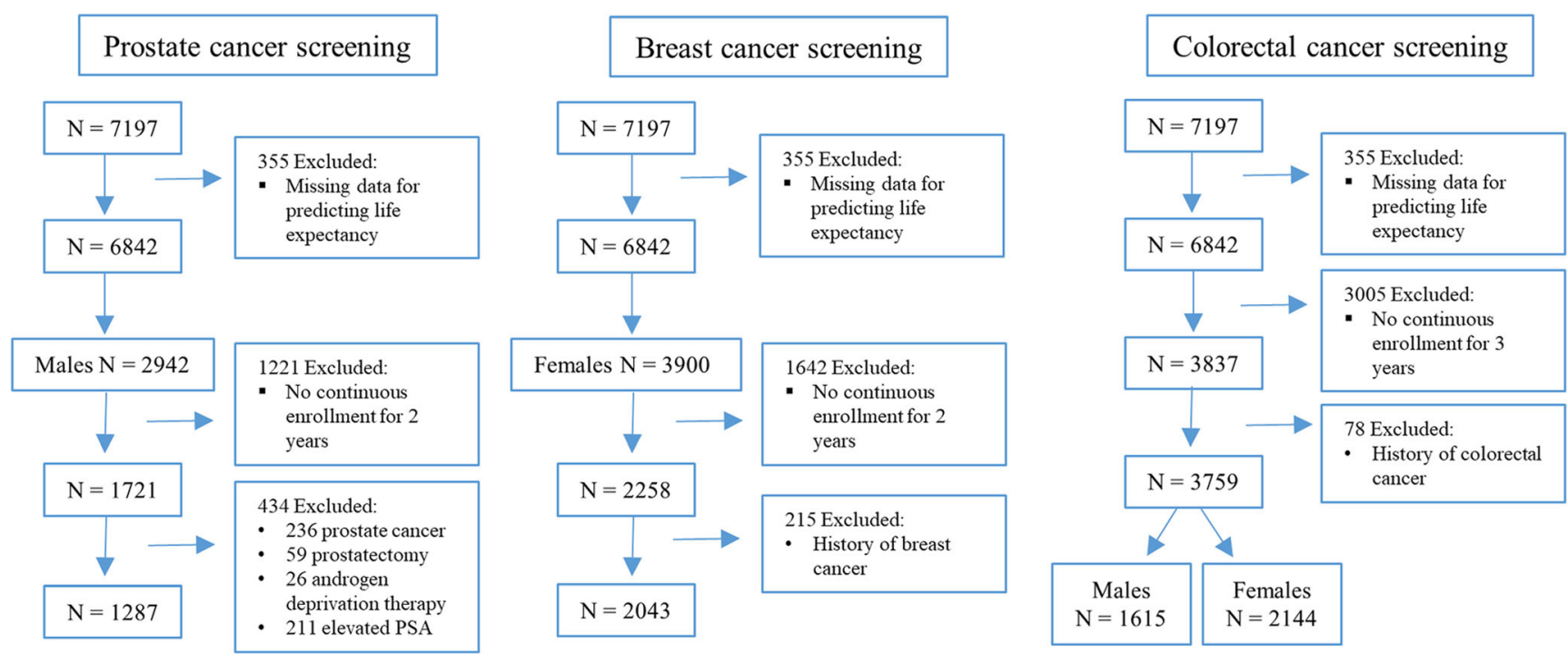

Figure 1 Construction of the three study analytic samples for prostate, breast, and colorectal cancer screening respectively. 
Table 1 The Mortality Risk Index by Lee et al. ${ }^{24,37}$

\begin{tabular}{|c|c|c|c|c|}
\hline \multicolumn{3}{|c|}{ Index items } & \multicolumn{2}{|c|}{ Mortality risk prediction } \\
\hline & & & $\begin{array}{l}\text { Total points } \\
(0-26)\end{array}$ & $\begin{array}{l}\text { 10-year mortality } \\
\text { risk \% (95\% CI) }\end{array}$ \\
\hline \multirow[t]{6}{*}{ Age } & $60-64$ & 1 point & 0 & $2.8(1.3-4.2)$ \\
\hline & $65-69$ & 2 points & 1 & $4.0(2.6-5.4)$ \\
\hline & $70-74$ & 3 points & 2 & $6.0(4.8-7.3)$ \\
\hline & $75-79$ & 4 points & 3 & $9.1(7.6-11)$ \\
\hline & $80-84$ & 5 points & 4 & $14(12-16)$ \\
\hline & $\geq 85$ & 7 points & 5 & $21(19-23)$ \\
\hline \multicolumn{2}{|c|}{ Male sex } & 2 points & 6 & $30(27-33)$ \\
\hline \multicolumn{2}{|c|}{$\begin{array}{l}\text { Body mass } \\
\text { index }<25\end{array}$} & 1 point & 7 & $40(36-43)$ \\
\hline \multicolumn{2}{|c|}{ Diabetes } & 1 point & 8 & $52(48-55)$ \\
\hline \multicolumn{2}{|c|}{ Cancer } & 2 points & 9 & $62(58-66)$ \\
\hline \multicolumn{2}{|c|}{$\begin{array}{l}\text { Chronic lung } \\
\text { disease }\end{array}$} & 2 points & 10 & $71(67-76)$ \\
\hline \multicolumn{2}{|c|}{ Heart failure } & 2 points & 11 & $81(76-85)$ \\
\hline \multicolumn{2}{|c|}{ Smoking } & 2 points & 12 & $85(81-90)$ \\
\hline \multicolumn{2}{|c|}{$\begin{array}{l}\text { Difficulty with } \\
\text { bathing or } \\
\text { showering }\end{array}$} & 2 points & 13 & $89(85-94)$ \\
\hline \multicolumn{2}{|c|}{$\begin{array}{l}\text { Difficulty } \\
\text { managing }\end{array}$} & 2 points & $\geq 14$ & $95(93-98)$ \\
\hline \multicolumn{2}{|c|}{$\begin{array}{l}\text { Difficulty } \\
\text { walking several } \\
\text { blocks }\end{array}$} & 2 points & & \\
\hline \multicolumn{2}{|c|}{$\begin{array}{l}\text { Difficulty with } \\
\text { pulling or } \\
\text { pushing large } \\
\text { objects }\end{array}$} & 1 point & & \\
\hline
\end{tabular}

status (difficulty bathing or showering, difficulty managing money, difficulty walking several blocks, and difficulty pushing/pulling large objects). ${ }^{24}$ The sum of the points from all items (maximum possible 26 points) is then used to calculate 10 -year mortality risk ranging from $2.8 \%$ in the lowest risk group with 0 points to $95 \%$ in the highest risk group with $\geq 14$ points. ${ }^{24}$ Body mass index was calculated from selfreported height and weight. For the Lee index question that asked about difficulty with pulling or pushing large objects such as a living room chair, we relied on the NHATS question which asks about difficulty carrying 20 pounds.

\section{Analytic Approach}

We first compared the screening rate by predicted median life expectancy $(<10$ years versus $>10$ years $)$ using chi-square test. For colorectal cancer, we stratified the analysis by sex since male sex is associated with increased mortality risk and is one of the items in the Lee index.

Next, we examined whether the screening rates differed by age among those with limited life expectancy, while holding predicted life expectancy constant. To accomplish this, we stratified participants at each level of predicted mortality risk (e.g., with the same Lee index score) and split participants within each mortality risk stratum by median age. We then assembled a younger sub-group and an older sub-group from these strata. Since the two sub-groups were matched on the same predicted mortality risk, those who were in the younger sub-group by definition had more comorbidities and/or functional deficits than their older counterparts in order to accrue the same amount of total mortality risk points. This allowed us to compare the screening rates between participants who were relatively younger with poorer health and/or functional status versus those who were older with relatively better health and/or functional status but with the same predicted life expectancy. The comparison of screening rates was accomplished by chisquare test. We hypothesize that among older adults with limited life expectancy (defined as $>50 \%$ 10-year mortality risk), those who are relatively younger (for example, those in their 60-70s) but have poor health status and/or poor functional status are more likely to receive cancer screening than those who are older (for example, those in their 80s), despite the same predicted life expectancies. All analyses were performed using SAS 9.4 software and incorporated the survey design variables and sampling weights. ${ }^{30}$

\section{RESULTS}

The final analytic sample included 1287 men in the prostate cancer screening cohort, 2043 women in the breast cancer screening cohort, and 3759 older adults (2144 women, 1615 men) in the colorectal cancer screening cohort (Fig. 1). Characteristics of the three analytic samples are shown in Table 2. Among the three cohorts, $36.7-45.6 \%$ had limited life expectancy of $<10$ years according to the Lee index. Those with more limited life expectancy were older in age, had lower self-rated health, had more cognitive impairment, and had lower educational level (all $p<0.001$ ). Compared to participants with $10+$ years of life expectancy, those with limited life expectancy were screened at lower but still substantial rates for all three types of cancers (Table 2). Below, we present the screening rates by age sub-groups among those with limited life expectancy for each type of cancer screening. As expected, the younger sub-groups had more comorbidities and more functional deficits than the older sub-groups but had similar predicted mortality rate over 10 years and had similar observed mortality rate during the observation periods (Table 3).

Prostate Cancer Screening. Among the participants in the analytic sample who had $<10$-year life expectancy, overall screening rate was $38.4 \%$. The average ages in the two subgroups were 73.4 and 83.6 years respectively. The younger sub-group had a screening rate of $42.9 \%$ and the older subgroup had a screening rate of $34.2 \%(p=0.02)$.

Breast Cancer Screening. Among the participants in the analytic sample who had $<10$-year life expectancy, overall screening rate was $27.0 \%$. The average ages in the two subgroups were 75.8 and 86.9 years respectively. The younger sub-group had a screening rate of $33.6 \%$ and the older subgroup had a screening rate of $20.6 \%(p<0.001)$. 
Table 2 Study Participant Characteristics

\begin{tabular}{|c|c|c|c|c|c|c|c|c|c|}
\hline & \multicolumn{3}{|c|}{$\begin{array}{l}\text { Prostate cancer screening } \\
N=\mathbf{1 2 8 7}\end{array}$} & \multicolumn{3}{|c|}{$\begin{array}{l}\text { Breast cancer screening } \\
N=\mathbf{2 0 4 3}\end{array}$} & \multicolumn{3}{|c|}{$\begin{array}{l}\text { Colorectal cancer screening } \\
N=\mathbf{3 7 5 9}\end{array}$} \\
\hline & $<10$ y LE* & $>10$ y LE & $p$ & $<10$ y LE & $>10$ y LE & $p$ & $<10$ y LE & $>10$ y LE & $p$ \\
\hline Sample size $(\%)$ & $733(45.6 \%)$ & $554(54.4 \%)$ & \multirow{3}{*}{$\begin{array}{l}< \\
0.001\end{array}$} & $973(36.7 \%)$ & $\begin{array}{l}1070 \\
(63.3 \%)\end{array}$ & \multirow{3}{*}{$\begin{array}{l}< \\
0.001\end{array}$} & $\begin{array}{l}1997 \\
(42.0 \%)\end{array}$ & $\begin{array}{l}1762 \\
(58.0 \%)\end{array}$ & \\
\hline Age, mean (SD) & $78.6(0.3)$ & $71.3(0.2)$ & & $81.5(0.3)$ & $72.7(0.2)$ & & $80.1(0.2)$ & $72.2(0.1)$ & \multirow[t]{2}{*}{$\stackrel{<}{0.001}$} \\
\hline $\begin{array}{l}\text { Age, median (range) } \\
\% \text { female }\end{array}$ & $\begin{array}{l}78.1(65.0 \\
100.0)\end{array}$ & $\begin{array}{l}69.7(65.0, \\
84.0)\end{array}$ & & $\begin{array}{l}81.5(65.0 \\
105.0)\end{array}$ & $\begin{array}{l}71.1(65.0, \\
91.0)\end{array}$ & & $\begin{array}{l}79.9(65.0 \\
105.0) \\
49.1 \%\end{array}$ & $\begin{array}{l}70.6(65.0, \\
91.0) \\
60.6 \%\end{array}$ & \\
\hline $\begin{array}{l}\text { Mortality risk points, } \\
\text { mean }(\mathrm{SD}) \\
\text { Self-rated health }\end{array}$ & $10.7(0.12)$ & $5.6(0.05)$ & $<.001$ & $10.8(0.09)$ & $4.6(0.05)$ & $<.001$ & $10.8(0.07)$ & $5.0(0.04)$ & $<.001$ \\
\hline Excellent & $8.2 \%$ & $24.4 \%$ & $<$ & $4.4 \%$ & $18.7 \%$ & $<$ & $6.3 \%$ & $19.7 \%$ & $<$ \\
\hline Very good & $19.2 \%$ & $37.4 \%$ & 0.001 & $16.8 \%$ & $36.3 \%$ & 0.001 & $18.8 \%$ & $38.0 \%$ & 0.001 \\
\hline Good & $30.3 \%$ & $25.0 \%$ & & $31.9 \%$ & $31.6 \%$ & & $32.4 \%$ & $29.3 \%$ & \\
\hline Fair & $28.5 \%$ & $11.4 \%$ & & $31.8 \%$ & $11.9 \%$ & & $28.6 \%$ & $11.5 \%$ & \\
\hline Poor & $13.8 \%$ & $1.8 \%$ & & $15.1 \%$ & $1.4 \%$ & & $13.9 \%$ & $1.5 \%$ & \\
\hline Educational level ${ }^{\star}$ & & & & & & & & & \\
\hline$<\mathrm{HS}$ & $28.4 \%$ & $16.6 \%$ & $<$ & $27.9 \%$ & $15.2 \%$ & $<$ & $27.0 \%$ & $14.2 \%$ & $<$ \\
\hline HS/GED & $31.7 \%$ & $27.0 \%$ & 0.001 & $41.5 \%$ & $39.7 \%$ & 0.001 & $35.8 \%$ & $35.2 \%$ & 0.001 \\
\hline $\begin{array}{l}>\mathrm{HS} \\
\text { Cognitive impairment }{ }^{\S}\end{array}$ & $39.9 \%$ & $56.5 \%$ & & $30.5 \%$ & $45.1 \%$ & & $37.2 \%$ & $50.7 \%$ & \\
\hline No dementia & $69.1 \%$ & $89.7 \%$ & $<$ & $63.3 \%$ & $90.7 \%$ & $<$ & $68.3 \%$ & $91.0 \%$ & $<$ \\
\hline Possible dementia & $14.2 \%$ & $7.6 \%$ & 0.001 & $13.6 \%$ & $6.1 \%$ & 0.001 & $13.8 \%$ & $6.3 \%$ & 0.001 \\
\hline Probable dementia & $16.7 \%$ & $2.7 \%$ & & $23.2 \%$ & $3.2 \%$ & & $17.9 \%$ & $2.7 \%$ & \\
\hline$\%$ received screening" & $38.4 \%$ & $55.6 \%$ & $\begin{array}{l}< \\
0.001\end{array}$ & $27.0 \%$ & $60.7 \%$ & $\begin{array}{l}< \\
0.001\end{array}$ & $13.1 \%$ & $25.4 \%$ & $\begin{array}{l}< \\
0.001\end{array}$ \\
\hline
\end{tabular}

*We defined limited life expectancy (LE) in this study as those with $>50 \%$ mortality risk, which corresponds to a median life expectancy less than 10 years

${ }^{+}$Based on the index by Lee et al. ${ }^{24}$ Total number of possible points ranges from 0 to 26

${ }^{7} H S$, high school; GED, general equivalency diploma; $y$, year

${ }_{\text {NHATS participants are classified into three groups according to an established scheme }}^{38}$

"Weighted percentages

Colorectal Cancer Screening. Among the participants in the analytic sample who had $<10$-year life expectancy, screening rate was $16.3 \%$ among males and $9.9 \%$ among females $(13.1 \%$ combined). Among the females, the average ages in the two sub-groups were 76.1 and 86.8 years respectively. The screening rate in the younger sub-group was significantly higher $(13.1 \%)$ than that of the older sub-group $(6.7 \%)$ with $p=$ 0.006 . Among the males, the average ages in the two subgroups were 73.8 and 83.8 years respectively. The screening rate in the younger sub-group was significantly higher $(20.5 \%)$ compared to the older sub-group (12.1\%) with $p=0.002$.

\section{DISCUSSION}

The findings of our analyses indicate that older adults with estimated life expectancy of less than 10 years still receive screening tests at substantial rates. These screening tests subject older adults to risks of screening when they have little chance of benefit, may lead to over-diagnosis and overtreatment of cancers, and detract from other more impactful health interventions. ${ }^{1-13}$ On the other hand, healthy older adults may be under-screened, for example, breast cancer screening rate is only $60.7 \%$ among older adults with $10+$ years of predicted life expectancy. This suggests missed opportunities for a significant number of healthy older women who may live long enough to benefit from screening.

The cancer screening rates found in NHATS, however, were lower than rates found in other national studies, both for those with normal and limited life expectancies. ${ }^{19}, 20,22,28$ For example, one study using National Health Interview Study data found screening rates among those with limited life expectancy and those with normal life expectancy ranged from $55-70 \%$ for prostate cancer, $38-74 \%$ for breast cancer, and $41-51 \%$ for colorectal cancer. ${ }^{19}$ The difference is potentially because these other studies relied on self-reported cancer screening rates whereas we used claims-based data to determine screening rates. Self-reported cancer screening rates have been shown to be prone to recall bias and over-estimate screening rates by up to $14 \%$ compared to claims or medical record review. ${ }^{39}$ Another potential reason for the lower screening rates in our study may be due to the inclusion of those participants who died before the end of observation periods. However, since the study focus is on older adults with limited life expectancy, we chose to include these participants in the analyses. A third potential explanation is that the screening rate overall has declined over time, since our project examined a more recent time period than previous studies. Declining screening rate over time has been suggested for breast and 
Table 3 Comparisons Between Younger and Older Sub-groups Among Those with < 10-Year Predicted Life Expectancy

\begin{tabular}{|c|c|c|c|}
\hline \multicolumn{4}{|l|}{ Prostate cancer screening* } \\
\hline & Younger sub-group & Older sub-group & $p$ \\
\hline Age (mean) & 73.4 & 83.6 & $<0.001$ \\
\hline Age, median (range) & $72.4(65.0,87.0)$ & $82.5(75.0,100.0)$ & \\
\hline Mortality risk score from health conditions ${ }^{\dagger}$ & 3.2 & 1.8 & $<0.001$ \\
\hline Mortality risk score from functional deficits & 2.1 & 1.3 & $<0.001$ \\
\hline Total mortality risk score ${ }^{\S}$ & 10.6 & 10.7 & 0.80 \\
\hline Predicted 10 -year mortality risk & $71.4 \%$ & $71.6 \%$ & 0.85 \\
\hline Percent died during observation period (2011-2013) & $18.3 \%$ & $14.4 \%$ & 0.20 \\
\hline Screening rate & $42.9 \%$ & $34.2 \%$ & 0.02 \\
\hline \multicolumn{4}{|l|}{ Breast cancer screening } \\
\hline Age (mean) & 75.8 & 86.9 & $<0.001$ \\
\hline Age, median (range) & $75.6(65.0,88.0)$ & $85.9(80.0,105.0)$ & \\
\hline Mortality risk score from health conditions ${ }^{\dagger}$ & 3.0 & 1.7 & $<0.001$ \\
\hline Mortality risk score from functional deficits & 3.9 & 2.8 & $<0.001$ \\
\hline Total mortality risk score & 10.8 & 10.9 & 0.57 \\
\hline Predicted 10-year mortality risk & $72.9 \%$ & $73.4 \%$ & 0.69 \\
\hline Percent died during observation period (2011-2013) & $16.6 \%$ & $17.1 \%$ & 0.85 \\
\hline Screening rate & $33.6 \%$ & $20.6 \%$ & $<0.001$ \\
\hline \multicolumn{4}{|l|}{ Colorectal cancer screening in women } \\
\hline Age (mean) & 76.1 & 86.8 & $<0.001$ \\
\hline Age, median (range) & $75.8(65.0,88.0)$ & $85.8(80.0,105.0)$ & \\
\hline Mortality risk score from health conditions ${ }^{\dagger}$ & 3.2 & 1.8 & $<0.001$ \\
\hline Mortality risk score from functional deficits & 3.8 & 2.8 & $<0.001$ \\
\hline Total mortality risk score ${ }^{\S}$ & 10.8 & 10.9 & 0.76 \\
\hline Predicted 10 -year mortality risk & $73.1 \%$ & $73.4 \%$ & 0.83 \\
\hline Percent died during observation period (2011-2014) & $21.6 \%$ & $27.0 \%$ & 0.06 \\
\hline Screening rate & $13.1 \%$ & $6.7 \%$ & 0.006 \\
\hline \multicolumn{4}{|l|}{ Colorectal cancer screening in men } \\
\hline Age (mean) & 73.8 & 83.8 & $<0.001$ \\
\hline Age, median (range) & $73.2(65.0,87.0)$ & $82.8(75.0,100.0)$ & \\
\hline Mortality risk score from health conditions ${ }^{\dagger}$ & 3.3 & 1.9 & $<0.001$ \\
\hline Mortality risk score from functional deficits & 2.0 & 1.2 & $<0.001$ \\
\hline Total mortality risk score ${ }^{\S}$ & 10.7 & 10.7 & 0.77 \\
\hline Predicted 10 -year mortality risk & $71.6 \%$ & $71.7 \%$ & 0.86 \\
\hline Percent died during observation period (2011-2014) & $19.9 \%$ & $21.6 \%$ & 0.59 \\
\hline Screening ratell & $20.5 \%$ & $12.1 \%$ & 0.002 \\
\hline
\end{tabular}

*All values except screening rates are averages unless otherwise noted

${ }^{\dagger}$ Weighted score assigned in the Lee mortality index related to health, including 1 point for low body mass index, 1 point for diabetes, 2 points for cancer, 2 points for lung disease, 2 points for congestive heart failure, 2 points for smoking. Total possible 10

${ }^{*}$ Weighted score assigned in the Lee mortality index related to function, including 2 points for difficulty with bathing, 2 points for difficulty managing finances, 2 points for difficulty walking, and 1 point for difficulty pushing/pulling large objects. Total possible 7

${ }^{\xi}$ Total mortality risk scores range from 0 to 26. In addition to the above health and function-related scores, 2 points for male sex and up to 7 points for various ages from 60 to $85+$

"Weighted percentages

prostate cancer screenings. ${ }^{40,41}$ For colorectal cancer screening, studies suggest increased screening over time, ${ }^{20,42}$ and the low colorectal screening rate in our study likely reflects under-estimation due to the observation period being constrained to 3 years.

Our study extends the previous work by relying on claimsbased assessments of cancer screening utilization and leveraging the rich health and functional status from the NHATS survey data to estimate life expectancy. Our study is also novel in that we assessed screening rates in a time period subsequent to, rather than preceding, the time point where life expectancy is estimated. Previous studies using only survey data often gathered information that were used to estimate life expectancy while asking about screenings in the past. ${ }^{19,} 20,27-29$ Our approach is arguably more accurate in assessing the extent of over-screening in those with limited life expectancy since life expectancy tends to decrease over time. If screening rates are measured several years before life expectancy assessment, it is conceivable that life expectancy at the time of screening was long enough to justify screening. By measuring screening rate after life expectancy assessment, this type of misclassification is much less likely.

To our knowledge, this is the first study to examine the influence of age versus health and functional status among individuals with closely matched predicted mortality risk. Compared to previous studies where mortality risk was categorized by quartiles of risk (i.e., all those with 9-year mortality risk from 50 to $74 \%$ were analyzed together in a single group), ${ }^{19}, 20,27-29$ we stratified the participants in our study into finer mortality risk strata (intra-stratum mortality risk ranged from $<5$ to $9 \%$ ) so as to minimize residual confounding and better isolate the effect of age on cancer screening independent of mortality risk. Previous studies had found contradicting results. Regarding breast cancer screening, one study found that within each mortality risk category, there was no difference in the screening rate by age. ${ }^{27}$ On the other hand, two other studies found that younger age was associated with receipt of screening mammograms even after controlling for 
mortality risk categories. ${ }^{28,}{ }^{29}$ Regarding colorectal cancer screening, one study found that younger age and lower mortality risk were both associated with higher screening but another study found that only age, but not mortality risk, was associated with screening. ${ }^{19,}{ }^{20}$ We examined three types of cancer screening, including prostate cancer screening which has only been examined in one previous study in terms of the relationship between age, life expectancy, and receipt of cancer screening. ${ }^{19}$ We found that among those with the same extent of limited life expectancy, younger participants with poorer health and/or functional status received significantly higher screening rates compared with those who were older with relatively better health or functional status. The trend was consistent across all three types of cancer screening. This result extends the previous literature and supports our hypothesis that those who have limited life expectancy primarily due to poor health and/or functional status but are relatively younger are particularly prone to being over-screened.

Several reasons may explain this finding. First, cancer screening guidelines have traditionally used age as metrics to guide screening decisions. ${ }^{9-11}$ More recently, research has advocated using life expectancy, which incorporates not only age but also an individual's health and functional status, to inform screening decisions. ${ }^{43}$ The adoption of this framework in cancer screening guidelines is variable - some guidelines recommend stopping screening based on either a specific age (most often $>75$ years old for breast, colorectal, and prostate cancers) or limited life expectancy ( $<10$ years); ${ }^{15,18,44}$ some guidelines use limited life expectancy alone; ${ }^{13}, 17,36$ still others use age cutoffs alone while acknowledging the importance of considering life expectancy and other competing causes of mortality. ${ }^{9}, 10,16$ How to approach the cancer screening decision in a patient who is younger than 75 with limited life expectancy is not clear. Further, clinicians have reported pressure to adhere to age-based screening guidelines, in part due to health system performance metrics that are based on these guidelines, and fear of litigation if they chose to deviate from these guidelines. ${ }^{26}$ The health system is increasingly shifting to value-based care focused on quality but quality metrics are still often defined by age-based screening guidelines; this leads to high risk of misaligned incentives that reward over-screening in patients who are relatively younger but have limited life expectancy. ${ }^{45}$ More consensus in the guidelines and practical ways to implement quality metrics that incorporate patients' life expectancies are needed.

Second, it is possible that clinicians do not always recognize poor health or functional deficits as predictors of limited life expectancy or that screening is not indicated in these scenarios. Third, younger patients may be more likely to want or request continued screening, since older adults report older age as a common reason for them to decide to stop screening. ${ }^{46}$ Future studies are needed to better understand the causes of the high rates of screening in this population, for whom the harms of screening may outweigh the benefits, in order to craft appropriate interventions. More education is likely needed among both clinicians and patients to recognize that poor health and functional status may be indicators that screening is no longer recommended. The results also highlight the importance to reconcile guidelines that use age and those that use life expectancy to guide when routine screening should stop.

Our study has a number of limitations. We adapted the Lee index to be used in the NHATS; although much of the same information is collected, the wording of some questions is not identical and may lead to different results of predicted life expectancy. However, we do not expect the general trend of our findings to be significantly altered. We used published algorithm to identify screening tests in the claims, but claims data can be susceptible for coding error and these algorithms may not be completely accurate. ${ }^{31-33}$ We were only able to assess colorectal cancer screening during a 3-year interval when screening colonoscopy is usually recommended every 10 years and screening sigmoidoscopy every 5 years. Therefore, we were not able to assess colonoscopies within 10 years or sigmoidoscopies within 5 years but outside our observation period to identify participants who were not yet due for screening during the study period; this likely resulted in under-estimation of the colorectal screening rate in our study. We were not able to further delineate if health status versus functional status had differential impact on the receipt of screening. Our study only included those participants with continuous Medicare fee-forservice coverage and more work is needed to confirm if the results also apply to older adults covered by Medicare Advantage plans. Lastly, this study does not allow for examination of the role of patient preference in screening decisions.

In summary, we found that a substantial proportion of older adults with limited life expectancy still receive breast, prostate, and colorectal cancer screenings while healthy older adults with $10+$ years of life expectancy may be under-screened. Furthermore, those who are relatively younger with poorer health or functional status are over-screened at even higher rates compared to those who are older, despite having the same predicted life expectancy. Understanding the causes for this discrepancy is critical for identifying targets for intervention to reduce over-screening in this vulnerable population.

Corresponding Author: Nancy L. Schoenborn, MD, MHS; The Johns Hopkins School of Medicine, Baltimore, MD, USA (e-mail: nancyli@jhmi.edu).

Author Contributions Dr. Schoenborn had full access to all of the data in the study and takes responsibility for the integrity of the data and the accuracy of the data analysis. Study concept and design: Schoenborn, Huang, Sheehan, Wolff, Roth, Boyd. Data analysis and interpretation: Schoenborn, Huang, Sheehan, Wolff, Roth, Boyd. Preparation and review of the manuscript: Schoenborn, Huang, Sheehan, Wolff, Roth, Boyd.

Funding/Support This project was made possible by the Johns Hopkins Institute for Clinical and Translational Research (ICTR) which is funded in part by KL2TR001077 from the National Center for Advancing Translational Sciences (NCATS), a component of the National Institutes of Health (NIH), and NIH Roadmap for Medical Research. Its contents are solely the responsibility of the authors and do not necessarily represent the official view of the Johns Hopkins ICTR, NCATS, or NIH. Dr. Schoenborn was also 
supported by a R03 from the National Instituteon Aging (R03AG050912), a Cancer Control Career Development Award from the American Cancer Society (CCCDA-16-002-01) and a T. Franklin Williams Scholarship Award (funding provided by the Atlantic Philanthropies, Inc., the John A. Hartford Foundation, the Alliance for Academic Internal Medicine-Association of Specialty Professors, and the American Geriatrics Society). Dr. Boyd was supported by 1K24AG056578 from the National Institute on Aging. The funding sources had no role in the design, methods, subject recruitment, data collections, analysis, and preparation of paper.

\section{Compliance with Ethical Standards}

This project was approved by a Johns Hopkins School of Medicine institutional review board.

Conflict of Interest. The authors declare no conflicts of interest. Dr. Cynthia Boyd received a small payment from UptoDate for having coauthored a chapter on Multimorbidity; however, we do not believe this has resulted in any conflict with the design, methodology, or results presented in this manuscript.

Prior Presentations. We have presented an earlier version of the manuscript as a poster at the 2018 Annual Beeson Scholars Meeting November 1-4, 2018 in Charlott, NC.

\section{REFERENCES}

1. Walter LC, Covinsky KE. Cancer screening in elderly patients: A framework for individualized decision making. JAMA. 2001;285(21):2750-2756.

2. Lee SJ, Boscardin WJ, Stijacic-Cenzer I, et al. Time lag to benefit after screening for breast and colorectal cancer: Meta-analysis of survival data from the united states, sweden, united kingdom, and denmark. BMJ. 2013;346:e8441.

3. Eckstrom E, Feeny DH, Walter LC, et al. Individualizing cancer screening in older adults: A narrative review and framework for future research. J Gen Intern Med 2013;28(2):292-298.

4. Walter LC, Schonberg MA. Screening mammography in older women: A review. JAMA 2014;311(13):1336-1347.

5. Day LW, Kwon A, Inadomi JM, et al. Adverse events in older patients undergoing colonoscopy: A systematic review and meta-analysis. Gastrointest Endosc 2011;74(4):885-896.

6. Kistler CE, Kirby KA, Lee D, et al. Long-term outcomes following positive fecal occult blood test results in older adults: Benefits and burdens. Arch Intern Med. 2011;171(15):1344-1351.

7. Day LW, Walter LC, Velayos F. Colorectal cancer screening and surveillance in the elderly patient. Am J Gastroenterol. 2011;106(7):1197-206; quiz 1207.

8. Ilic D, Neuberger MM, Djulbegovic M, et al. Screening for prostate cancer. Cochrane Database Syst Rev. 2013;1:CD004720.

9. U.S. Preventive Services Task Force. Screening for colorectal cancer: U.S. Preventive Services Task Force recommendation statement. Ann Intern Med. 2008;149(9):627-37.

10. U.S. Preventive Services Task Force. Screening for breast cancer: U.S. Preventive Services Task Force recommendation statement. Ann Intern Med. 2009;151(10):716-26.

11. Moyer VA, U.S. Preventive Services Task Force. Screening for prostate cancer: U.S. preventive services task force recommendation statement. Ann Intern Med. 2012;157(2):120-134.

12. U.S. Preventive Services Task Force. Screening for prostate cancer: U.S. Preventive Services Task Force recommendation statement. Ann Intern Med. 2008; 149(3): 185-91.

13. Oeffinger KC, Fontham ET, Etzioni R, et al. Breast cancer screening for women at average risk: 2015 guideline update from the American Cancer Society. JAMA. 2015;314(15):1599-614.

14. Reuben DB. Medical care for the final years of life: "when you're 83, it's not going to be 20 years". JAMA. 2009;302(24):2686-2694.

15. Qaseem A, Barry MJ, Denberg TD, et al, Clinical Guidelines Committee of the American College of Physicians. Screening for Prostate Cancer: A Guidance Statement From the Clinical Guidelines Committee of the American College of Physicians. Ann Intern Med. 2013;158(10):761-769
16. Carter HB, Albertsen PC, Barry MJ, et al. Early detection of prostate cancer: AUA guideline. J Urol 2003;190(2):419-426.

17. Society of General Internal Medicine. Five things physicians and patients should question - the choosing wisely campaign. 2013. http://www. choosingwisely.org/wp-content/uploads/2013/09/SGIM-5things-List_ 091213.pdf. Accessed Sept 2014.

18. Gaseem A, Denberg TD, Hopkins RH, et al. Screening for Colorectal Cancer: A Guidance Statement From the American College of Physicians. Ann Intern Med. 2012;156(5):378-86.

19. Royce TJ, Hendrix LH, Stokes WA, et al. Cancer screening rates in individuals with different life expectancies. JAMA Intern Med. 2014; 174(10): 1558-65.

20. Schonberg MA, Breslau ES, Hamel MB, et al. Colon cancer screening in U.S. adults aged 65 and older according to life expectancy and age. J Am Geriatr Soc 2015;63(4):750-756.

21. Powell AA, Saini SD, Breitenstein MK, et al. Rates and correlates of potentially inappropriate colorectal cancer screening in the veterans health administration. J Gen Intern Med. 2015;30(6):732-741.

22. Drazer MW, Prasad SM, Huo D, et al. National trends in prostate cancer screening among older american men with limited 9-year life expectancies: Evidence of an increased need for shared decision making. Cancer. 2014;120(10):1491-1498.

23. So C, Kirby KA, Mehta K, et al. Medical center characteristics associated with PSA screening in elderly veterans with limited life expectancy. J Gen Intern Med. 2012;27(6):653-660.

24. Cruz M, Covinsky K, Widera EW, et al. Predicting 10-year mortality for older adults. JAMA. 2013;309(9):874-876.

25. Schonberg MA, Davis RB, McCarthy EP, et al. External validation of an index to predict up to 9-year mortality of community-dwelling adults aged 65 and older. J Am Geriatr Soc. 2011;59(8):1444-1451

26. Schoenborn NL, Bowman TL, Cayea D, et al. Primary care practitioners' views on incorporating long-term prognosis in the care of older adults. JAMA Intern Med. 2016;176(5):671-8

27. Koya DL, Chen JG, Smith TG, Moran WP. Screening mammography use in Medicare beneficiaries reflects 4-year mortality risk. Am J Med. 2011;124(4):369.e1-8.

28. Williams BA, Lindquist $\mathbf{K}$, Sudore RL, Covinsky KE, Walter LC. Screening mammography in older women. Effect of wealth and prognosis. Arch Intern Med. 2008;168(5):514-20.

29. Schonberg MA, Breslau ES, McCarthy EP. Targeting of mammography screening according to life expectancy in women aged 75 and older. J Am Geriatr Soc. 2013;61(3): 388-95.

30. Montaquila J, Freedman VA, Edwards B, et al. Round 1 Sample Design and Selection. NHATS Technical Paper \#1. Baltimore: Johns Hopkins University School of Public Health. 2012. Available at: https://www. nhats.org/scripts/sampling/NHATS_Round 1_Sample_Design_05_10_ 12.pdf. Accessed 11 Aug 2017.

31. Walter LC, Bertenthal $\mathbf{D}$, Lindquist $\mathbf{K}$, et al. PSA screening among elderly men with limited life expectancies. JAMA. 2006;296(19):2336-42.

32. Fenton JJ, Zhu W, Balch S, et al. Distinguishing screening from diagnostic mammograms using medicare claims data. Med Care. 2014;52(7): e44-51.

33. Mittal S, Lin YL, Tan A, et al. Limited life expectancy among a subgroup of medicare beneficiaries receiving screening colonoscopies. Clin Gastroenterol Hepatol. 2014; 12(3):443-450.

34. Wolf AMD, Wender RC, Etzioni RB, et al. American Cancer Society Guideline for the Early Detection of Prostate Cancer: Update 2010. CA Cancer J Clin. 2010;60(2):70-98

35. Rex DK, Johnson DA, Anderson JC, et al. American College of Gastroenterology guidelines for colorectal cancer screening 2009. Am J Gastroenterol. 2009;104(3):739-50.

36. Schnipper LE, Lyman GH, Blayney DW, et al. American society of clinical oncology 2013 top five list in oncology. J Clin Oncol. 2013;31(34):4362-4370.

37. Lee SJ, (2006) Development and validation of a prognostic index for 4year mortality in older adults. JAMA 295(7):801

38. Kasper JD, Freedman VA, Spillman BC. Classification of persons by dementia status in the National Health and Aging Trends Study. NHATS Technical Paper \#5, Baltimore: Johns Hopkins University School of Public Health. 2013. Available at: https://www.nhats.org/scripts/documents/DementiaTechnicalPaperJuly_2_4_2013_10_23_15.pdf. Accessed 1 Nov 2017.

39. Rauscher GH, Johnson TP, Cho YI, et al. Accuracy of self-reported cancer-screening histories: a meta-analysis. Cancer Epidemiol Biomark Prev. 2008;17(4):748-57.

40. Chang CH, Bynum JP, Onega T, Colla CH, Lurie JD, Tosteson AN. Screening mammography use among older women before and after the 
2009 U.S. Preventive Services Task Force recommendations. J Womens Health (Larchmt). 2016;25(10): 1030-1037.

41. Jemal A, Fedewa Sa, Ma J, et al. Prostate cancer incidence and PSA testing patterns in relation to USPSTF screening recommendations. JAMA. 2015;314(19):2054-61.

42. Rao SR, Breen N, Graubard BI. Trends in black-white disparities in breast and colorectal cancer screening rates in a changing screening environment: the peters-belson approach using united states national health interview surveys 2000-2010. Med Care. 2016;54(2):133-9.

43. Lee SJ, Kim CM. Individualizing prevention for older adults. J Am Geriatr Soc. 2018;66(2):229-234.

44. Wilt TJ, Harris RP, Qaseem A, High Value Care Task Force of the American College of Physicians. Screening for Cancer: Advice for HighValue Care From the American College of Physicians. Ann Intern Med. 2015; 162(10):718-25

45. Saini SD, Vijan S, Schoenfeld $\mathbf{P}$, et al. Role of quality measurement in inappropriate use of screening for colorectal cancer: retrospective cohort study. BMJ. 2014;348:g1247.

46. Schoenborn NL, Lee K, Pollack CE, et al. Older adults' views and communication preferences around cancer screening cessation JAMA Intern Med. 2017;177(8):1121-1128.

\section{APPENDIX. ALGORITHMS USED TO IDENTIFY BREAST, PROSTATE, AND COLORECTAL CANCER SCREENING IN MEDICARE CLAIMS DATA}

\section{Screening mammograms}

We used a three-step algorithm to distinguish screening from diagnostic mammograms validated by Fenton et al. ${ }^{32}$

(1) Include if mammography was for screening (76092, 77057, G0202, any GG modifier, G0203/05); exclude if mammography was for diagnosis (76090, 76091, 77055, 77056, G0204, G0206);

(2) Exclude mammography if the woman has already received mammography in the prior 9 months;

(3) Exclude if any ICD-9 code for breast cancer in the prior year $(174 x, 233.0$, V103, 611.72);

\section{Screening prostate-specific antigen (PSA) test}

We used the algorithm used by Walter et al. ${ }^{31}$

PSA test: CPT code G0103 and 84153.

We excluded men who were ineligible for screening either due to prior history or symptoms (in the 3 months prior to PSA testing) that suggested the test was more likely to be diagnostic rather than screening:

Prior history:

- Prostate cancer (ICD-9 185, V1046)

- Prostatectomy (ICD-9 60.21, 60.29, 60.3-60.6, 60.61, 60.62, 60.69, CPT 55810, 55812, 55815, 55801, 55821, $55831,55842,55845)$

- Androgen deprivation therapy (CPT J1950, J9202, J9217, J9218, J9219)

- History of elevated PSA (ICD-9 790.93)

Symptoms:

- Urinary obstruction (ICD-9 599.6)
- Hematuria (ICD-9 599.7)

- Prostatitis (ICD-9 601-601.9)

- Other disorders of the prostate (ICD-9 602-602.9)

- Unexplained weight loss (ICD-9 783.21)

- Back pain (ICD-9 724.5)

\section{Colorectal cancer screening}

Colonoscopy: we used the algorithm used by Mittal et al. ${ }^{33}$ which included CPT codes 45378 45380, 45382, 45383, 45384, 45385, HCPCS codes G0105, G0121, and ICD-9 codes 45.23, 45.25, 45.27, 45.41, 45.42, 45.43 .

Sigmoidoscopy: we used CPT codes 45300, 45303, 45305, 45308, 45309, 45315, 45320, 45330, 45331, 45332, 45333, 45334, 45337, 45338, 45339, and HCPCS code G0104 (Maroongroge et al. JCO 2018;41(4):339-347)

Fecal occult blood test: we used CPT codes 82270, 82272, 82273, 82274, and HCPCS code G0107, G0328. (Maroongroge et al. JCO 2018;41(4):339-347)

For all three types of screening modalities, we excluded patients if they had symptoms or diagnoses that suggested the test was more likely to be diagnostic rather than screening ${ }^{33}$ :

- High risk diagnoses: history of colon cancer (153.0, 153.1, 153.2, 153.3, 153.4, 153.6, 153.7, 153.8, 153.9, 154.0, 154.1, 230.3, 230.4, V10.05, V10.06), inflammatory bowel diseases (555.0, 555.1, 555.2, 555.9., 556.0, 556.1, 556.4, 556.9, 556.2, 556.6. 556.8, 556.5), and other conditions where a colonoscopy might plausibly be indicated (260- $263,558.1$, $560.2,560.30,560.39,793.4,783.21,569.82,558.1,569.2$, 569.41, 569.61, 569.62, 569.69, 569.81, 569.82, 596.1, 710.3, 863.44, 863.45, 936, 997.4, V44.3, V45.3, V55.3, V58.42, V58.49, V58.75, V67.0, V67.1, V67.9).

- Anemia (280.0, 280.1, 280.8, 280.9, 281.0, 281.8, 281.9, 285.1, 285.2, 285.9)

- Gastrointestinal bleeding (286.5, 459.0, 562.02, 562.03, $562.12,562.13,569.3,569.84,569.85,569.86,578.1$, 578.9, 792.1, 998.11).

- Other related symptoms: constipation (564.0, 564.00, $564.09,564.01,564.02)$, diarrhea $(008.42,008.43,008.45$, 008.5, 008.8, 009.0-009.3, 558.2, 558.3, 558.9, 564.4, 564.5, 564.8, 564.9, 787.91), abdominal pain (789.0, 787.3, 789.4, 789.6), ischemic bowel disease $(557.0,557.1,557.9)$, irritated bowel syndrome (564.1), bowel habits change (787.99), hemorrhoid (455), and weight loss (783.2, 783.7).

- Diverticulitis (562.11).ACCEPTED MANUSCRIPT

- Barium enema: CPT codes 74270, 74280, HCPCS codes G0106, G0120, G0122 and ICD-9-CM procedure code 87.64.

- Abdominal computerized tomographic scan: CPT codes 72191, 72192, 72193, 72194, 74150, 74160, 74170, $74175,75635,74261,74262,74263$ and ICD-9-CM procedure codes $88.01,88.02$. 